\title{
Effects of V2G Reactive Power Compensation on the Component Selection in an EV or PHEV Bidirectional Charger
}

\author{
Mithat C. Kisacikoglu ${ }^{1}$, Burak Ozpineci ${ }^{2}$, and Leon M. Tolbert ${ }^{1,2}$ \\ 'Dept. of Electrical Engineering and Computer Science \\ The University of Tennessee \\ Knoxville, TN 37996-2100 \\ ${ }^{2}$ Power and Energy Systems Group \\ Oak Ridge National Laboratory \\ Oak Ridge, TN 37831
}

\begin{abstract}
Electric vehicles (EVs) and plug-in hybrid electric vehicles (PHEVs) are becoming a part of the electric grid day by day. Chargers for these vehicles have the ability to make this interaction better for the consumer and for the grid. Vehicle to grid (V2G) power transfer has been under research for more than a decade because of the large energy reserve of an electric vehicle battery and the potential of thousands of these connected to the grid. Rather than discharging the vehicle batteries, reactive power compensation in particular is beneficial for both consumers and for the utility. However, certain adverse effects or requirements of reactive power transfer should be defined before a design stage. To understand the dynamics of this operation, this study investigates the effect of reactive power transfer on the charger system components, especially on the de-link capacitor and the battery.
\end{abstract}

Index Terms-Battery, bidirectional charger, charger, electric vehicle, EV, PHEV, reactive power, V2G.

\section{NOMENCLATURE}

$v_{d c}(t) \quad$ instantaneous dc link voltage, [V]

$V_{d c} \quad$ average dc link voltage [V],

$\Delta V_{d c} \quad$ peak-to-peak dc ripple voltage [V],

$C_{d c} \quad$ dc link capacitor [F].

$v_{c}(t) \quad$ instantaneous charger voltage [V],

$V_{c} \quad$ rms charger input voltage [V]

$v_{s}(t) \quad$ instantaneous line voltage [V],

$V_{s} \quad$ rms line voltage [V],

$i_{c}(t) \quad$ instantaneous charger current [A],

$I_{c} \quad$ rms line current $[\mathrm{A}]$,

$i_{\text {conv }}(t)$ instantaneous dc-dc converter input current [A],

$I_{\text {conv }} \quad$ average bidirectional converter input current [A],

$i_{d c}(t) \quad$ inverter output current on the dc side [A],

$i_{\text {cap }}(t) \quad$ instantaneous de link capacitor current [A],

$I_{\text {cap }} \quad$ rms de link capacitor current [A],

$I_{\text {cap,low }}$ rms low harmonic current of de capacitor [A],
$I_{\text {cap }, P W M}$ rms PWM harmonic current of dc capacitor [A],

$P_{s} \quad$ active power supplied to/from grid [W],

$Q_{s} \quad$ reactive power supplied to/from grid [VAr],

$Q_{c} \quad$ reactive power supplied to/from charger [VAr],

$Q_{L} \quad$ reactive power of the coupling inductance [VAr],

$E_{a c} \quad$ energy calculated at the ac side [J],

$E_{d c} \quad$ energy calculated at the dc side [J],

$L_{c} \quad$ coupling inductor [H],

$\delta \quad$ phase angle of $v_{c}(t)$ with respect to $v_{s}(t)$,

$\theta$ phase angle of $i_{c}(t)$ with respect to $v_{s}(t)$,

$\varphi \quad$ phase angle of $v_{d c}(t)$ with respect to $v_{s}(t)$,

$w \quad$ angular frequency of line voltage $[\mathrm{rad} / \mathrm{s}]$, $\begin{array}{ll}w_{1} & \text { angular frequency of the de link voltage ripple } \\ {[\mathrm{rad} / \mathrm{s}]} & \end{array}$

\section{INTRODUCTION}

According to the international energy outlook report, the transportation sector is going to increase its share in world's total oil consumption by up to $55 \%$ by 2030 [1]. Compared to liquid carbon-based energy transportation, storing energy electrochemically in batteries is more reliable, cleaner, and local way of storing transportation energy due to wide availability and cleaner generation/transmission of electricity as an energy source [2].

The term electric vehicles (EV) will be used for both all-electric and plug-in hybrid electric vehicles throughout this paper. EV power electronics and related control systems are the system components that will make this new technology feasible and are more important than the current battery technology challenges [3]. One important component having potential for development is the EV battery charger. It can strengthen the interaction between the grid and the vehicle so that neither of them is harmed in the short and long term. An advanced charger performs several functions in addition to the charging operation for better grid integration. While these functions are described 
in the next section in detail, in short, the utility can get support from the charger either by controlling the charging power delivered by the grid or by controlling a bidirectional charger to supply power to the grid from the vehicles.

The economical and technical aspects of using EVs to support the electric grid have been studied since 1997 [411]. Recent papers including [8-11] have discussed several topologies and control methods that can perform bidirectional power transfer using EVs as a distributed energy resource. However, in the literature, there has not been much technical analysis of reactive power compensation or any other grid support function using bidirectional EV chargers as well as the effects of these on the battery and charger system components.

In [12], the authors show that compared to peak power shaving, reactive power regulation causes no degradation on battery life, since the dc link capacitor is enough to supply full reactive power for Level 1 charging without engaging the EV battery. Level 1 charging requires $120 \mathrm{~V}$ single phase standard ac outlet with $12 \mathrm{~A}$ maximum line current. Level 2 charging is rated 208 to $240 \mathrm{~V}$ single phase outlet with up to $32 \mathrm{~A}$ line current capacity [13].

The purpose of this paper is to mathematically analyze reactive power compensation and to extend the study done in [12] so that Level 2 charging is also included and power transfer limitations of the system are observed. The authors investigate different scenarios to deliver the stored energy from the vehicle to the grid and explain the effects of this on the vehicle traction battery and the charger capacitor. In Section III, the application potential for bidirectional chargers is explained. In Section IV, the topology used in this paper is described. In Section V, an analysis of the overall system is shown to understand the impacts of V2G power transfer on charger components. In Section VI, simulation results are given to verify the analytical results. Finally, future planned studies are presented.

\section{MultipurPose APPLICATIONS USING EV CHARGERS}

EV chargers are of critical importance to strengthen the interaction between the grid and the vehicle in a responsible way so that neither vehicle nor grid is harmed in the short and long term. A simple unidirectional charger is enough to charge a vehicle battery with required voltage and current waveforms. In contrast, an advanced charger is capable of performing several functions during charging operation to make the grid integration beneficial to the utility and the owner of the vehicle.

One type of interaction is called demand-side management. It corresponds to responding to utility signals during charging operation to provide continuous adjustment of charging power to keep the electric grid as stable as possible [14]. Secondly, the vehicle can send active and reactive power to the grid when there is a need for support by the utility. This support is called V2G, the acronym for vehicle-to-grid power transfer. It involves using the parked vehicles for distributed energy generation. Usually, a vehicle stays parked during $90-95 \%$ of their total lifetime. Therefore, the utility can benefit from this valuable asset and utilize alternative vehicle technologies, an expensive investment. The third outcome of this interaction is to utilize the excess energy produced by renewable energy resources (RES) such as wind turbines, especially during nights when vehicles will be connected for daily charging. The capital value of the RES equipment will also be utilized in this case.

EV chargers can provide the grid with the following services that can be included in V2G: 1) voltage support, 2) reactive power compensation, 3) harmonic filtering, 4) power factor regulation, 5) load balancing, and 6) peak shaving. Also, if the grid electricity is lost, the charger should be suitable for islanded operation for emergency power which is often called vehicle-to-home (V2H) or vehicle-to-any load (V2X).

Drawbacks of including add-on values to the charger are increased number and size for the components. Coupled with this, each of the objectives should be treated separately to define the net increase in the required size for the components such as dc-link capacitor. Also the control circuitry and programming needs to be more sophisticated to incorporate extra functions. Lastly, the utility will have to provide the required communication signals and should determine the needed functions and upgrades in the neighborhood distribution system where the vehicles are plugged in.

In addition, the main problems with supplying active power with vehicle batteries are the reduced state of charge of the battery and an increase in the time required to fully charge the battery. The system efficiency for charging and discharging a battery is in the $60 \%$ to $80 \%$ range. What is more, to replace the same amount of active power into the battery, the vehicle must stay plugged in to the grid for a longer time because of the losses in battery and charger. Because of the two-way power flow, this time is inversely proportional to twice the efficiency of the total system.

Therefore, using EV chargers to give reactive power support to grid may be more preferential in terms of consumer expectations and system efficiencies. Such a grid conditioning charger can facilitate the widespread use of charging stations to charge electric vehicles.

\section{SYSTEM DESCRIPTION}

The PHEV charger in this study is composed of a fullbridge inverter/rectifier and a half bridge bi-directional dcdc converter as shown in Fig. 1. This topology has less component count compared to more complex topologies but still operates with low line current THD while supporting four quadrant operation. It is easy to control to fulfill the required objectives of the charger. Although the 


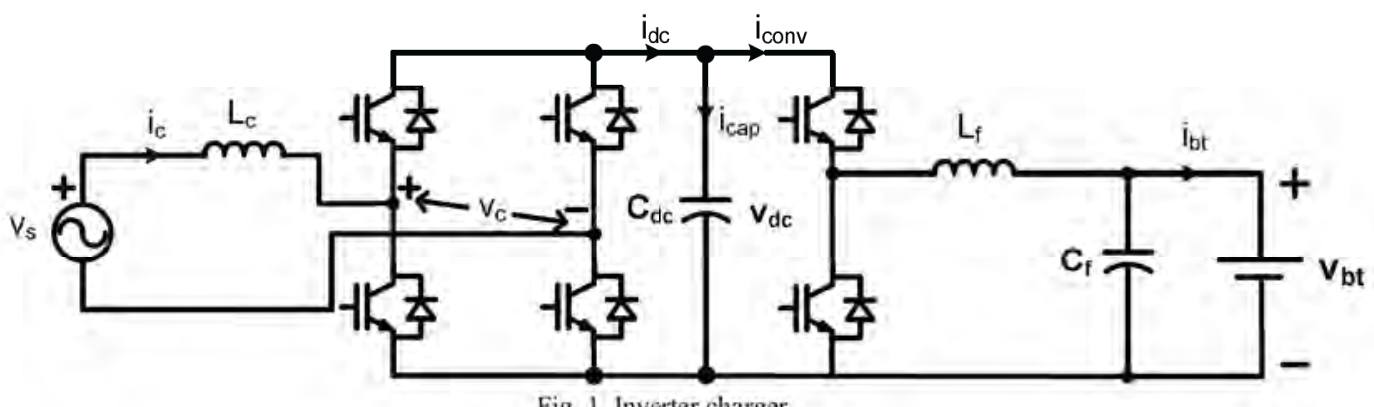

Fig. 1. Inverter charger.

topology is more efficient with less number of power conversion stages, it does not provide galvanic isolation.

The flexibility of this topology enables the same converter to be used for different applications such as reactive and active power regulation with PV, fuel cell, ultracapacitors, and end-of-life Li-ion vehicle batteries. Moreover, the dc link of the vehicle charger can have a direct connection to the renewable dc sources such as fuel cell and PV to minimize the power conversion stages. Also, if a vehicle is out of charge without a nearby charging station, another vehicle would be able to charge it using the same dc connection of the converter.

Since the charger is operating like a current source, it is important that it complies with IEEE 1547 [15] to present the minimum current harmonics possible. Therefore, a hysteresis-band current control PWM is used to effectively regulate the current waveform, and the control algorithm limits the switching frequency. Current magnitude and its phase angle are selected to be the variables of the control algorithm.

\section{Mathematical Analysis of the Charger}

The feasibility of using a PHEV charger for reactive power support to grid can be determined by checking for adverse effects on the PHEV components. Rather than conducting time-based simulation analysis, a mathematical approach is needed to facilitate the analysis of the system operation for different working modes, given in Table I. In this study, the effects of different operation modes on the design stage of the inverter will be given. Considering the charger is designed to operate at full power mode, the rms line current stays at its maximum irrespective of the operation mode. Therefore, design of the coupling inductor does not depend on the operation mode. Rather, it depends on the maximum rms line current. For this study, a $5 \mathrm{mH}$ coupling inductor is chosen based on literature search. Mathematical analysis on how to select the dc link capacitor will be given in this section. During the analysis, the positive current direction will be assumed to be from grid to the inverter as shown in Fig. 1. Therefore, positive power sign $(\mathrm{P}=$ active power and $\mathrm{Q}=$ reactive power $)$ corresponds to the power flow from grid to the inverter.
For this analysis, the following parameters should be calculated based on the different operation modes of the charger: dc link voltage, ripple current, and ripple voltage. To select an appropriate dc link voltage level for the system, the relation between dc voltage and power should be understood first.

One conclusion aimed at this study was to understand the relation between dc variables of the charger and the magnitude of the reactive power transfer to grid. If the grid voltage is constant, grid reactive power $\left(Q_{s}\right)$ only changes with phase angle or magnitude of the line current. Therefore, the magnitude of the reactive power does not depend on the dc parameters of the system. However, reactive power $\left(Q_{s}\right)$ compared with the same amount of active power $\left(P_{s}\right)$ may have more effect on the dc components such as dc link capacitor. Therefore, this study examines the relation between reactive power and dc link capacitor voltage and current.

\section{A. Dc Link Voltage Analysis}

To facilitate the formulation, all PWM ripples generated by the switching actions of the charger are neglected. These ripples contribute to the total ripple current requirement of the dc link capacitor which will be explained in the next discussion.

The grid and charger voltage is assumed to be purely sinusoidal, i.e.:

TABLE I. CHARGER OPERATION MODES

\begin{tabular}{|l|l|l|l|}
\hline$\#$ & P & Q & Operation Mode of the Charger \\
\hline 1 & Zero & Positive & Inductive \\
\hline 2 & Zero & Negative & Capacitive \\
\hline 3 & Positive & Zero & Charging \\
\hline 4 & Negative & Zero & Discharging \\
\hline 5 & Positive & Positive & Charging and inductive \\
\hline 6 & Positive & Negative & Charging and capacitive \\
\hline 7 & Negative & Positive & Discharging and inductive \\
\hline 8 & Negative & Negative & Discharging and capacitive \\
\hline
\end{tabular}




$$
\begin{aligned}
& v_{s}(t)=\sqrt{2} V_{s} \sin (\omega t), \\
& v_{c}(t)=\sqrt{2} V_{c} \sin (\omega t-\delta),
\end{aligned}
$$

In order to ensure power transfer from charger to the utility, an inductor is used to decouple the two voltage sources $v_{c}(t)$ and $v_{s}(t)$. Applying necessary mathematical transformations, the line current can be written as:

$$
i_{c}(t)=\sqrt{2} I_{c} \sin (\omega t-\theta) .
$$

Since the default direction for active and reactive power transfer is from grid to charger, $i_{c}(t)$ and $v_{c}(t)$ are lagging the grid voltage. Also, note that the reactance is equal to

$$
X_{c}=2 \pi f L_{c},
$$

where $f$ is the system frequency. It is assumed that the dc link voltage has a positive phase angle $\varphi$ with respect to line voltage and it is defined by the following formula:

$$
v_{d c}(t)=V_{d c}+\frac{\Delta V_{d c}}{2} \cdot \sin \left(\omega_{1} t+\varphi\right) .
$$

It is important to note that the angular frequency of the ripple voltage is different from the line voltage angular frequency. Similarly, the dc link capacitor current is found by applying derivative of (5):

$$
i_{c a p}(t)=C_{d c} \cdot \omega_{i} \frac{\Delta V_{d c}}{2} \cdot \cos \left(\omega_{1} t+\varphi\right) .
$$

In a lossless system, the input active power to the charger is equal to the active power delivered to the dc-dc converter to charge the battery. Therefore,

$$
I_{\text {conv }} \cdot V_{d c}=V_{s} \cdot I_{c} \cdot \cos (\theta) .
$$

As a result,

$$
I_{\text {conv }}=V_{s} \cdot I_{c} \cdot \cos (\theta) / V_{d c} .
$$

The total dc current of the inverter is

$$
i_{d c}(t)=i_{\text {conv }}(t)+i_{\text {cap }}(t) .
$$

The maximum voltage increase on the capacitor occurs when it is charged from its minimum charge state to maximum state of charge as shown in Fig. 2. Therefore, assuming the system is lossless and the energy is conserved, the total energy needed to charge the capacitor from its minimum to maximum voltage will be the same for the ac and dc side of the system:

$$
\int_{t_{\min }}^{t_{\max }} v_{d c}(t) i_{d c}(t) d t=\int_{t_{\min }}^{t_{\max }} v_{c}(t) i_{c}(t) d t .
$$

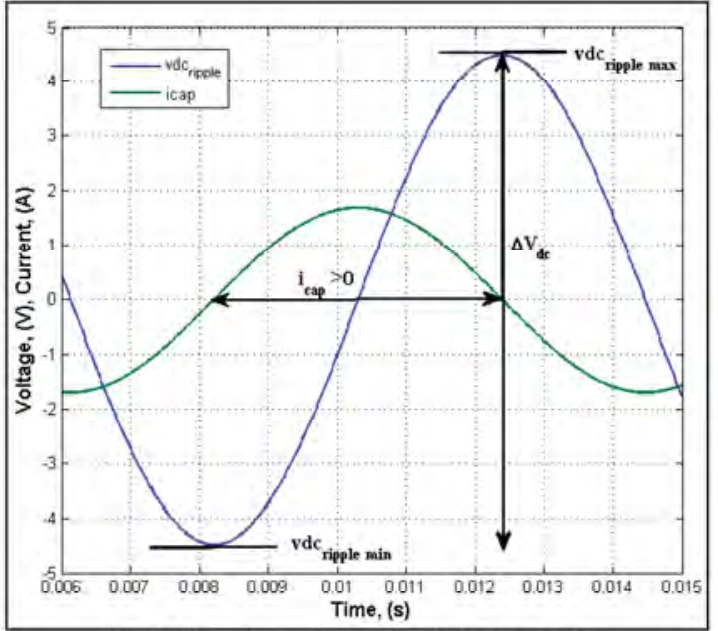

Fig. 2. Charging action of the dc link capacitor.

Recalling (5) yields the times where the minimum and maximum voltage occurs:

$$
\begin{aligned}
& t_{\min }=1 / \omega_{1}(-\pi / 2-\varphi), \\
& t_{\max }=1 / \omega_{1}(\pi / 2-\varphi) .
\end{aligned}
$$

Therefore, the energy at the dc side required to charge the capacitor is

$$
\begin{aligned}
& E_{d c}={ }_{t_{\min }}^{t_{\max }} v_{d c}(t) i_{d c}(t) d t, \\
& E_{d c}=V_{s} \cdot I_{c} \cdot \cos (\theta) \cdot \pi / \omega_{1}+V_{d c} \cdot C_{d c} \cdot \Delta V_{d c}
\end{aligned}
$$

Similarly, the ac side energy is calculated. Note that the angular frequency at the ac side is different from the dc side.

$$
E_{a c}(t)={ }_{t_{\min }}^{t_{\max }} v_{c}(t) i_{c}(t) d \omega t .
$$

It is a well known fact that $\omega_{l}$, in a single phase inverter, equals to $2 \omega$. Therefore, $E_{a c}(t)$ can be expressed as

$$
=V_{c} I_{c} \cos (\theta-\delta) \frac{\pi}{\omega_{1}}-\frac{1}{\omega} V_{c} I_{c} \cos (\varphi+\delta+\theta)
$$

If the system is lossless, (14) should be equal to (16). Comparing (14) to (16), the first terms of both equations are the same and represent active power transfer component of the total energy. Therefore, the second terms are equal to each other also. The sign conventions for both of the equations stand for consumed energy. Therefore, one equals to the opposite sign of the other. This yields: 


$$
\Delta V_{d c}=\frac{V_{c} \cdot I_{c} \cdot \cos (\varphi+\delta+\theta)}{V_{d c} \cdot \omega \cdot C_{d c}}
$$

Here the angle $\varphi$ is found by comparing simulation and analytical results. All the other dependent variables are also listed here:

$$
\begin{aligned}
& \varphi=-\theta-\delta, \\
& \theta=\tan ^{-1}\left(Q_{s} / P_{s}\right), \\
& I_{c}=\sqrt{\left(P_{s}^{2}+Q_{s}^{2}\right)} / V_{s}, \\
& \delta=\tan ^{-1}\left(X_{c} \cdot P_{s} /\left(V_{s}^{2}-X_{c} \cdot Q_{s}\right)\right),
\end{aligned}
$$

and,

$$
V_{c}=P_{s} \cdot X_{c} /\left(V_{s} \cdot \sin (\delta)\right) .
$$

If all the dependent variables are plugged in into (17), the following equation can be derived:

$$
\Delta V_{d c}=\frac{\sqrt{\left[P_{s}^{2} \cdot X_{c}^{2}+\left(V_{s}^{2}-X_{c} \cdot Q_{s}\right)^{2}\right] \times\left[P_{s}^{2}+Q_{s}^{2}\right]}}{V_{s} \cdot \omega \cdot C_{d c} \cdot V_{d c}}
$$

In summary, the ripple voltage can be written as a function of different design parameters:

$$
\Delta V_{d c}=g\left(P_{s}, Q_{s}, C_{d c}, L_{c}, V_{s}, V_{d c}, f\right) .
$$

Equation (24) confirms that the dc link voltage ripple hence maximum dc link voltage changes with different active and reactive power levels, coupling inductance, dclink capacitance, line voltage, dc-link voltage, and line frequency. Equation (23) gives important conclusions on how to select the dc link capacitor. First, the voltage ripple is related to the operation mode of the charger. If the charger is assumed to operate with full capacitive operation, i.e. Mode $\# 2$ in Table I, $Q_{s}$ becomes negative and voltage ripple becomes the highest. Therefore, increased voltage ripple should be expected for that operation.

Second, the dc link voltage value is inversely proportional to the capacitance. Therefore, a combination of dc link voltage value and capacitance value should be selected. It is important to note that the lowest dc link voltage value should be higher than sum of required battery charging voltage and the voltage drops at the dc-dc converter. Once the $V_{d c}$ is selected, the calculated $\Delta V_{d c}$ will give the maximum value of the dc link capacitor. The selected dc link capacitor should have a voltage rating higher than this maximum value.

Consequently, for a given charger, line voltage, $V_{s}$, and line frequency, $f$, are already known. Also, the active power $P_{s}$, and reactive power $Q_{s}$ are commands controlled by the utility. Therefore the independent design parameters that affect the dc ripple voltage are dc-link capacitor, $C_{d c}$, coupling inductor, $L$, and dc-link voltage, $V_{d c}$.

\section{B. Dc Link Current Analysis}

Using the bipolar hysteresis current control, the dc side current will always be equal to ac side current but the direction of $i_{d c}(t)$ changes from positive to negative in each switching cycle. Therefore, the total rms current on the ac side, $I_{c}$, is always equal to the total rms current on the dc side, $I_{d c}$. Therefore, assuming a large capacitor, the total ripple current on the dc link capacitor is equal to:

$$
I_{\text {cap }}=\sqrt{I_{c}^{2}-I_{c o n v}^{2}}=\sqrt{I_{c}^{2}-\left(P_{s} / V_{d c}\right)^{2}}
$$

The low frequency component of this current is already given by (6). It can be simplified using (17):

$$
I_{\text {cap low }}=\frac{V_{c} I_{c}}{\sqrt{2} V_{d c}} .
$$

The PWM ripple component of the capacitor current is:

$$
I_{c a p, P W M}=\sqrt{I_{c}^{2}-\left(P_{s} / V_{d c}\right)^{2}-I_{c a p, l o w}^{2}}
$$

It is important to distinguish the low and high frequency current components of the capacitor since the rating of the capacitor is chosen based on the ripple frequency. In the next section, the analysis results for both voltage and currents will be given.

\section{Simulation Results}

The mathematical analysis results for the capacitor voltage are first compared to a time domain simulation using PLECS software. All the active and passive components used in the simulation are ideal as assumed in the mathematical analysis. The computed peak-peak dc link voltage ripple is close to the simulation results as shown in Fig. 3.

Figure 4 shows the effect of different operation modes on the Level 2 charger. In this case, a $500 \mathrm{~V}, 500 \mu \mathrm{F} \mathrm{dc}$ link capacitor is used. The Level 2 charger is always operated at its rated power of $7 \mathrm{kVA}$. The grid voltage is $240 \mathrm{~V}$, system frequency is $60 \mathrm{~Hz}$, and coupling inductor is $5 \mathrm{mH}$. Active and reactive power changes with phase angle.

A $90^{\circ}$ phase shift corresponds to inductive operation, Mode \#1, where the ripple voltage is minimum. In contrast, a $270^{\circ}$ phase shift corresponds to capacitive operation (Mode \#2) and requires the highest peak-peak ripple from the de link capacitor. As illustrated in Fig. 4, $0^{\circ}$ phase shift corresponds to battery charging (Mode \#3), whereas $180^{\circ}$ phase shift corresponds to battery discharging (Mode \#4) where the battery provides active power to the grid. 


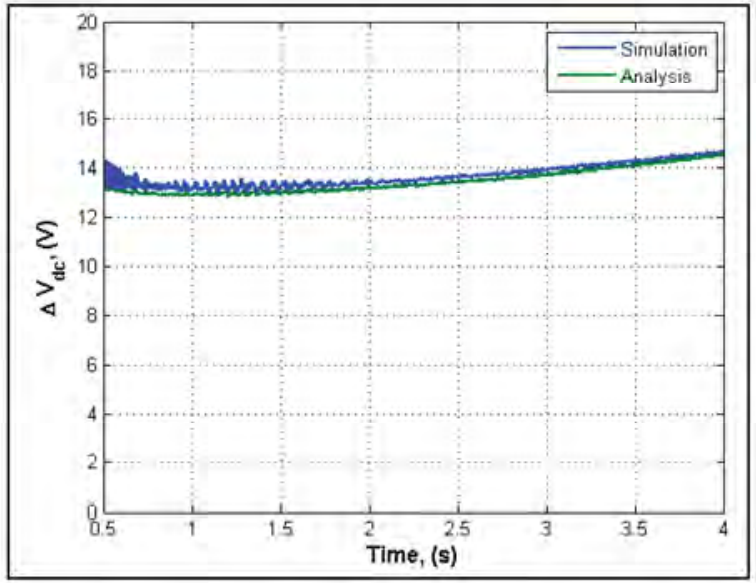

Fig. 3. Comparison of simulation and analysis data for de link voltage ripple during battery charging.

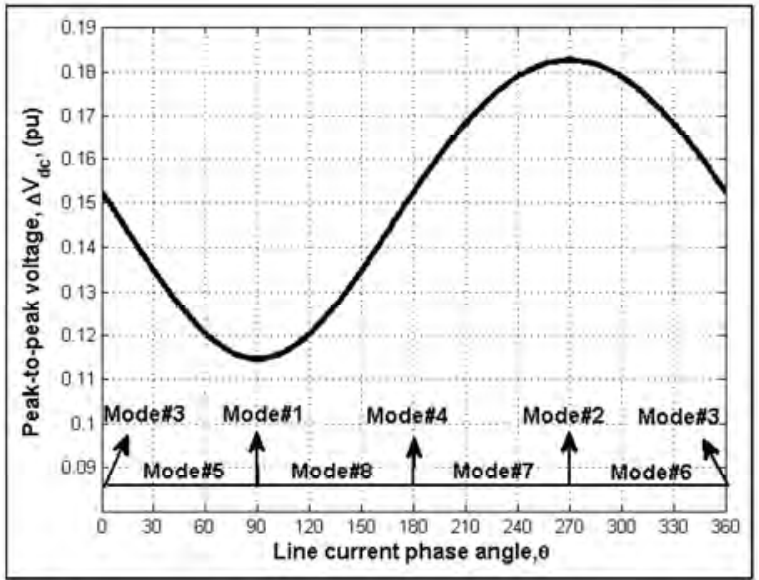

Fig. 4. Change of dc capacitor ripple voltage with different operation modes using a Level 2 charger.

The effect of reactive power to de link voltage will be higher if a smaller size capacitor is used. Therefore, when choosing a capacitor for a required dc voltage, the ripple voltage should be analyzed first and the capacitor should be selected accordingly so as not to exhaust an under estimated capacitor when working in the capacitive operation mode.

The various operation modes of the charger will also have different effects on ripple current of the capacitor. As explained earlier, the dc link capacitor has a second harmonic low frequency ripple and PWM high frequency ripple components. To distinguish the different frequencies is important to decide the correct frequency multiplier when choosing the capacitor.

Figure 5 shows the result of the mathematical analysis given in (25)-(27). The conditions are the same with the dc link voltage analysis. Total capacitor current ripple increases with reactive power transfer without any difference in power transfer direction. Inductive/capacitive operation (Mode \#1 and Mode \#2) requires the highest current ripple, and charging/discharging operation (Mode \#3 and Mode \#4) requires the lowest ripple. When sizing the capacitor, it is important to measure the maximum amount of low and high frequency ripples to prevent oversizing the capacitor.

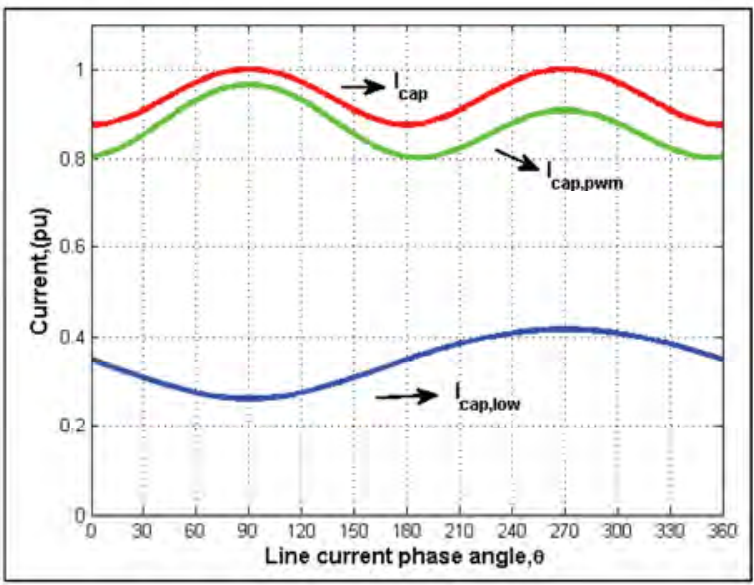

Fig. 5. Change of dc capacitor ripple current with different operation modes using a Level 2 charger.

Figure 5 illustrates that the capacitor needs to deliver up to $0.41 \mathrm{pu}$ (with $29 \mathrm{~A}$ base current for the Level 2 charger) low frequency current component to operate at full capacitive operation. In comparison, if the charger operated with only charging action this current would only be $0.35 \mathrm{pu}$. This corresponds to a $17 \%$ increase in a low frequency current demand from the capacitor if the charger supplies reactive power to grid. Since the low frequency current demand will be a restricting factor when choosing the capacitor, this change should be taken into consideration when designing the charger. Because this result is for a $500 \mathrm{~V}, 500 \mu \mathrm{F}$ capacitor, a smaller size capacitor will require a higher percentage increase for the low frequency component.

Active power transfer between grid and the charger $\left(0^{\circ}\right.$ and $180^{\circ}$ phase shifts) results in the same amount of peakto-peak voltage ripple without being affected by the direction of the active power flow. However, reactive power flow direction changes the dc link voltage ripple. If the charger is operated at capacitive mode when it sends reactive power to the grid, the maximum voltage ripple is observed among all other operation modes with the same apparent power. This difference is caused by the coupling inductance. The amount of reactive power that the coupling inductor introduces into the system can be given as:

$$
Q_{L}=\omega \cdot L_{c} \cdot I_{c}^{2} .
$$

Therefore, the net reactive power that the charger needs to absorb during inductive mode is equal to the following:

$$
Q_{c}=Q_{s}-Q_{L} \text {. }
$$


However, during capacitive operation mode, for the same amount of grid reactive power, charger needs to supply:

$$
Q_{c}=Q_{s}+Q_{L}
$$

As a result, the difference is equal to twice the reactive power that the coupling inductance uses. Therefore, this extra reactive power is translated as an increased ripple to the dc side. If the coupling inductance is decreased, the voltage and current ripple seen at the dc side will decrease and vice versa. Consequently, once a coupling inductor is chosen for the charger, the dc link capacitor should be selected based on the capacitive mode operation requirements of the charger since it demands the highest ripple requirements both in terms of voltage and current.

\section{CONCLUSION}

EV and PHEV chargers can achieve reactive power regulation if the charger is suitable to allow bidirectional power flow. However, different operation modes such as reactive power regulation or battery charging affect the components of the charger based on the component ratings of the charger. A designer should first decide the full operation objectives of the charger or should limit the operation of the charger based on the system component ratings. It is not straightforward to expect a full fourquadrant power transfer from a charger that is designed only to charge the battery. This study elaborates the effect of $\mathrm{V} 2 \mathrm{G}$ reactive power transfer on the charger components such as the dc link capacitor by relating the ac and dc side variables. Future study will be on including the analysis of the dc-dc converter and battery for reactive power support.

\section{REFERENCES}

[1] "International energy outlook 2009," Energy Information Administration, Office of Integrated Analysis and Forecasting, U.S. Department of Energy, Washington, DC. [Online]. Available: http://www.eia.doe/gov/oiaf/ieo/pdf/0484(2009).pdf

[2] "Size of oil spill underestimated, scientists say." The New York Times, 13 May 2010. [Online]. Available: http://www.nytimes.com/2010/05/14/us/14oil.html.
[3] A. Emadi, "Plug-in hybrid electric vehicles: transportation 2.0," Half-day tutorial presented at the 2009 IEEE Vehicle Power and Propulsion Conference (VPPC'09), Dearborn, MI, Sept. 2009.

[4] W. Kempton, A. E. Letendre, "Electric vehicles as a new source for electric utilities," Transport. Res. Part D Transport. Envir., vol. 2, no 3, pp. 157-175, September 1997.

[5] M. Bojrup, "Advanced Control of Active Filters in a Battery Charger Application" Licentiate Thesis Dept. Ind. Elec. Eng. and Automation, Lund Institute of Technology, 1999. [Online] Available: www.iea.lth.se/publications/Theses/LTH-IEA-102 la.pdf.

[6] S. D. Breucker, P. Jacqmaer, K. De Brabandere, J. Driesen, R. Belmans, "Grid power quality improvements using grid-coupled hybrid electric vehicles," 3rd IET International Conference on Power Electronics, Machines and Drives (PEMD 2006), Dublin, Ireland, 4-6 April 2006.

[7] "Bottling electricity: storage as a strategic tool for managing variability and capacity concerns in the modern grid," Electricity advisory committee, December 2008. [Online]. Available: www.oe.energy.gov/final-energy-storage 12-16-08.pdf.

[8] X. Zhou, S. Lukic, S. Bhattacharya, A. Huang, "Design and control of grid-connected converter in bi-directional battery charger for plug-in hybrid electric vehicle application," Vehicle Power and Propulsion Conference (VPPC'09), Dearborn, MI, USA, 7-10 September 2009, pp. 1716-1721.

[9] Y. Du, X. Zhou, S. Bai, S. Lukic, A. Huang, "Review of nonisolated bi-directional dc-de converters for plug-in hybrid electric vehicle charge station application at municipal parking decks," in Proc. 2010 IEEE Applied Power Electronics Conference and Exposition, pp. 1145-1151.

[10] I. Cvetkovic, et. al. "Future home uninterruptable renewable energy system with vehicle-to-grid technology," Energy Conversion Congress \& Exposition (ECCE'09), San Jose, CA, USA, September 20-24, 2009, pp. 2675-2681.

[11] D. C. Erb, O. C. Onar, A. Khaligh, "Bi-directional charging topologies for plug-in hybrid electric vehicles," in Proc. IEEE Applied Power Electronics Conference and Exposition, 2010, Palm Springs, California, pp. 2066-2072.

[12] M. C. Kisacikoglu, B. Ozpineci, L. M. Tolbert, "Examination of a PHEV bidirectional charger for $\mathrm{V} 2 \mathrm{G}$ reactive power compensation," in Proc. IEEE Applied Power Electronics Conference and Exposition, 2010, Palm Springs, California, pp. 458-465.

[13] SAE J1772 Electric vehicle conductive charge coupler and SAE J1773 Electric vehicle inductively coupled charging, Society for Automotive Engineers, Inc.

[14] L. Dickerman, J. Harrison, "A new car, a new grid," IEEE Power and Energy Magazine, vol. 8, no. 2, pp. 55-61, March-April 2010.

[15] IEEE 1547, Standard for Interconnecting Distributed Resources with Electric Power Systems. 